\title{
Demographics, Clinical Profile, Cause and Outcome of Epilepsy in Neurosurgical Unit in Manipal Teaching Hospital in Western Nepal
}

\author{
Suman Adhikari ${ }^{1}$, Prabin Bhandari ${ }^{1}$, Balgopal Karmacharya ${ }^{2}$, Nikunja Yogi ${ }^{2}$ \\ ${ }^{1}$ Medical Officer, Department of Neurosurgery, Manipal Teaching Hospital, Pokhara Nepal \\ ${ }^{2}$ Associate Professor, Department of Neurosurgery, Manipal Teaching Hospital, Pokhara Nepal \\ Correspondence: \\ Dr. Suman Adhikari \\ Medical Officer \\ Department of Neurosurgery \\ Manipal Teaching Hospital, Pokhara, Nepal \\ Email: dradhikarisuman@gmail.com
}

\begin{abstract}
Background: Epilepsy is a common chronic disorder characterized by recurrent unprovoked seizures. Around 50 million people worldwide have epilepsy and almost $80 \%$ of people with epilepsy live in low and middle-income countries. Most of these people do not get the necessary treatment they need. The main objective of this study is to study the demographic profile of patients, etiology of epilepsy and prescribing pattern, drug compliance, and its outcome in terms of epilepsy control in patients. Materials and methods: A retrospective analytical study was conducted from January 2018 to December 2018 including 120 consecutive patients admitted with epilepsy with an objective to study various clinico-socio-demographical features of epilepsy and various features associated with outcome. The outcome was categorized into a good outcome group and poor outcome group according to absence or decrease in seizure frequency in 6 months duration in comparison to the pre-treatment status. All the continuous variables were compared in relation to the outcome using the student's t-test and the categorical data were compared using Chi-square and Fischer Exact test. Data analysis was done using SPSS 20.0 software. Results: The mean age of the study population was $37.8 \pm 21.1$ years ( 4 months -95 years). Mean hospital stay was $11.97 \pm 11.5$ days. There were 79 $(65.83 \%)$ males and 41 (34.17\% females in the study. Ninety seven $(80.83 \%)$ of the patients in our were educated above high school level and literacy level showed statistically significant association with good seizure control $(\mathrm{p}=0.043)$. One hundred thirteen patients had Generalized Tonic-Clonic Seizures and 7 patients had a partial seizure. Levetiracetam $(52,43.3 \%)$ was the commonest antiepileptic used in our series, and polytherapy was used in $15(12.5 \%)$ of patients. Intracerebral hemorrhage $(39.2 \%)$ and Trauma (36.7\%) were the commonest cause of epilepsy in our series.Conclusion:Drug compliance played a pivotal role in determining good seizure control vs. poor seizure control. Additionally, the literacy level of the patient determined drug compliance and thus seizure control.
\end{abstract}

Key words: Anticonvulsants, Epilepsy, Neurosurgery,

$\mathrm{E}$ pilepsy is a common chronic disorder characterized by recurrent unprovoked seizures. An epileptic seizure refers to the transient occurrence of signs and/or symptoms due to abnormally excessive or synchronous neuronal activity in the brain. The epileptic seizure may be characterized by sensory, motor, or autonomic phenomena with or without loss of consciousness.
Around 50 million people worldwide have epilepsy and almost $80 \%$ of people with epilepsy live in low and middle-income countries. Most of these people epilepsy living in low-income countries do not get the treatment they need. ${ }^{1}$ This treatment gap may be due to limited knowledge, poverty, cultural beliefs, stigma, poor health delivery infrastructure, and shortage of trained health workers in these regions. ${ }^{2}$ Studies conducted in a tertiary hospital in central Nepal indicate that generalized tonic-clonic seizure is the most common seizure type. 
Neurocysticercosis is the most common cause of epilepsy in Nepal (47\%) and in India (50\%). ${ }^{3-5}$ The main objective of this study is to study the demographic profile of patients, etiology of epilepsy and prescribing pattern, drug compliance, and its outcome in terms of epilepsy control in patients.

\section{Methods and Materials:}

A retrospective analytical study was conducted in the Department of Neurosurgery, Manipal Teaching Hospital, Nepal from January 2018 to December 2018 including 120 consecutive patients admitted with epilepsy with an objective to study various clinico-socio-demographical features of epilepsy and various features associated with outcome. Epilepsy was diagnosed on history and clinical presentation. Imaging was done in all patients. Data was collected from the Medical Record Department, ICU census, files, and discharge sheets and charted in a pre-structured proforma. Epilepsy was described as two or more episodes of unprovoked documented seizures. Patients of all ages and both genders admitted in the neurosurgery ward and ICU were included in the study. Patients with pseudo seizure, inadequate data and those lost in follow up were excluded from the study. Data were collected on social demographical characteristics like age, gender, marital status, education, and clinical characteristics (drugs used, comorbidities, type of seizure, antiepileptic drugs, control with antiepileptic drugs, etc.). The outcome was categorized into a good outcome group and a poor outcome group. Good outcome was defined as absence or decrease in seizure frequency in 6 months duration in comparison to the pre-treatment status. Patients were followed up till 6 months with telephone conversation using a pre-structured questionnaire or scheduled OPD visit after the telephone conversation. All the continuous variables were compared in relation to the outcome using the student's t-test and the categorical data were compared using Chi-square and Fischer Exact test. Data analysis was done using SPSS20.0 software.

egneuro, Volume 02, Issue 02, 2020

\section{Results:}

The cases of one hundred and thirty-five patients who met all the inclusion and exclusion criteria were retrospectively studied. One hundred thirty five patients were initially included in the study but 15 were lost either in follow up or expired during treatment or left to other medical centers against medical advice. The final analysis was done for 120 patients. There were 79 male patients and 41 female patients. The mean age of the study population was $37.8 \pm 21.1$ years $(4$ months -95 years). Mean hospital stay was $11.97 \pm 11.5$ days.

One hundred thirteen patients had generalized tonic-clonic seizures and 7 patients had a partial seizure. Other seizure types were not reported in our study; probably because sample collection was done only from the neurosurgery department. The presence of a pediatric population in the sample size was minimal and patients managed under medical neurology were not included in the study. The variables gender, literacy, marital status, and seizure type were further categorized as having good control and poor control as illustrated inTable 1.

Table 1 Clinico-demographical profiles of patients and their outcomes

\begin{tabular}{|c|c|c|c|c|}
\hline S. $\mathbf{N}$ & Variable & $\begin{array}{c}\text { Good } \\
\text { control }\end{array}$ & Poor control & $\begin{array}{c}\text { P- } \\
\text { value }\end{array}$ \\
\hline \multirow[t]{3}{*}{1} & Gender & & & 0.642 \\
\hline & Female & $29(33.0 \%)$ & $12(37.5 \%)$ & \\
\hline & Male & $59(67.0 \%)$ & $20(62.5 \%)$ & \\
\hline \multirow[t]{3}{*}{2} & Literacy & & & $0.043^{*}$ \\
\hline & Uneducated & $13(14.8 \%)$ & $10(31.2 \%)$ & \\
\hline & Educated & $75(85.2 \%)$ & $22(68.8 \%)$ & \\
\hline \multirow[t]{4}{*}{3} & Marital status & & & 0.69 \\
\hline & Married & $53(60.2 \%)$ & $20(62.5 \%)$ & \\
\hline & Single & $33(37.5 \%)$ & $8(25.0 \%)$ & \\
\hline & Widow & $2(2.3 \%)$ & $4(12.5 \%)$ & \\
\hline \multirow[t]{3}{*}{4} & Seizure type & & & 1.000 \\
\hline & GTCS & $83(94.3 \%)$ & $30(90.8 \%)$ & \\
\hline & Partial & $5(5.7 \%)$ & $2(6.2 \%)$ & \\
\hline
\end{tabular}

The patients were additionally stratified according to their education level. Those who attended high school and above were categorized as educated and patients who attended below high school were categorized as uneducated. There was a statistically significant association between patients' education level and seizure control with the P-value of 0.043 . 
Antiepileptic drugs prescribed were Levetiracetam to $43.3 \%$ patients, phenytoin to $41.7 \%$ of patients, valproate to $21.7 \%$ of patients, carbamazepine to $4.2 \%$ of patients and others antiepileptic drugs to $3.3 \%$ of patients. The seizure control among prescribed antiepileptic drugs was further stratified into good outcomes and poor outcome as demonstrated in Table 2.

Table. 2 Prescribing patterns in epilepsy patients and their outcomes

\begin{tabular}{|c|c|c|c|c|}
\hline S. $\mathbf{N}$ & $\begin{array}{c}\text { Antiepileptic } \\
\text { drugs }\end{array}$ & $\begin{array}{l}\text { Good } \\
\text { control }\end{array}$ & $\begin{array}{c}\text { Poor } \\
\text { control }\end{array}$ & $\begin{array}{c}P \text { - } \\
\text { value }\end{array}$ \\
\hline \multirow[t]{3}{*}{1} & Valproate & & & 0.142 \\
\hline & No & $66(75.0 \%)$ & $28(87.5 \%)$ & \\
\hline & Yes & $22(25.0 \%)$ & $4(12.5 \%)$ & \\
\hline \multirow[t]{3}{*}{2} & Phenytoin & & & 0.577 \\
\hline & No & $50(56.8 \%)$ & $20(62.5 \%)$ & \\
\hline & Yes & $38(43.2 \%)$ & $12(37.5 \%)$ & \\
\hline \multirow[t]{3}{*}{3} & Carbamazepine & & & 1.000 \\
\hline & No & $84(95.5 \%)$ & $31(96.9 \%)$ & \\
\hline & Yes & $4(4.5 \%)$ & $1(3.1 \%)$ & \\
\hline \multirow[t]{3}{*}{4} & Levetiracetam & & & 0.956 \\
\hline & No & $50(56.8 \%)$ & $18(56.2 \%)$ & \\
\hline & Yes & $38(43.2 \%)$ & $14(43.8 \%)$ & \\
\hline \multirow[t]{4}{*}{5} & Other & & & 0.289 \\
\hline & Antiepileptics & & & \\
\hline & No & $86(97.7 \%)$ & $30(93.8 \%)$ & \\
\hline & Yes & $2(2.3 \%)$ & $2(6.2 \%)$ & \\
\hline \multirow[t]{3}{*}{6} & Therapy & & & 0.349 \\
\hline & Monotherapy & $75(85.2 \%)$ & $30(93.8 \%)$ & \\
\hline & Polytherapy & $13(14.8 \%)$ & $2(6.2 \%)$ & \\
\hline
\end{tabular}

$85.2 \%$ of patients with good control were under monotherapy. $14.8 \%$ of patients with good control were under polytherapy. $93.8 \%$ of patients with poor control were under monotherapy and $6.2 \%$ of patients with poor control were under polytherapy. The frequency of each cause of the seizure and further stratification according to seizure control is listed in Table 3.

Though previous studies showed neurocysticercosis to be the most common cause of epilepsy in Nepal, we found intracranial hemorrhage as the most common cause of epilepsy considering our sample collection from the neurosurgery department only. Systemic hypertension was the most common comorbidity associated with our sample size. $23.3 \%$ of patients were hypertensive and $3.3 \%$ of patients were diabetic. $2.5 \%$ of patients were both hypertensive and diabetic. No statistically significant association was found between these comorbidities and epilepsy control.Admission serum sodium and potassium level were also included as variables in the study but no statistical significance found between them and seizure control.

Table 3 Causes of epilepsy in our series and its outcome

\begin{tabular}{|c|c|c|c|c|}
\hline S. $\mathbf{N}$ & Cause & $\begin{array}{c}\text { Good } \\
\text { control }\end{array}$ & $\begin{array}{c}\text { Poor } \\
\text { control }\end{array}$ & $\begin{array}{c}P \text { - } \\
\text { value }\end{array}$ \\
\hline \multirow[t]{3}{*}{1} & Trauma & & & $0.004^{*}$ \\
\hline & No & $49(55.7 \%)$ & $27(84.4 \%)$ & \\
\hline & Yes & $39(44.3 \%)$ & $5(15.6 \%)$ & \\
\hline \multirow[t]{3}{*}{2} & Tumor & & & $0.007 *$ \\
\hline & No & $80(90.9 \%)$ & $22(68.8 \%)$ & \\
\hline & Yes & $8(9.1 \%)$ & $10(31.2 \%)$ & \\
\hline \multirow[t]{3}{*}{3} & ICH & & & 0.055 \\
\hline & No & $49(55.7 \%)$ & $24(75.0 \%)$ & \\
\hline & Yes & $39(44.3 \%)$ & $8(25.0 \%)$ & \\
\hline \multirow[t]{3}{*}{4} & Infection & & & 0.187 \\
\hline & No & $81(92.0 \%)$ & $32(100 \%)$ & \\
\hline & Yes & $7(8.0) \%)$ & $0(0.0 \%)$ & \\
\hline \multirow[t]{5}{*}{5} & Congenital & & & 0.731 \\
\hline & brain & $80(90.9 \%)$ & $28(87.5 \%)$ & \\
\hline & malformation & $8(9.1 \%)$ & $4(12.5 \%)$ & \\
\hline & No & & & \\
\hline & Yes & & & \\
\hline \multirow[t]{3}{*}{6} & Hydrocephalus & & & $0.014 *$ \\
\hline & No & $86(97.7 \%)$ & $27(84.4 \%)$ & \\
\hline & Yes & $2(2.3 \%)$ & $5(15.6 \%)$ & \\
\hline \multirow[t]{3}{*}{7} & Ischemic CVA & & & 0.828 \\
\hline & No & $65(73.9 \%)$ & $23(71.9 \%)$ & \\
\hline & Yes & $23(26.1 \%)$ & $9(28.1 \%)$ & \\
\hline
\end{tabular}

\section{Discussion:}

Though not much is not known about epilepsy in Nepal due to inadequate data, according to Rajbhandari KC its prevalence was $0.7 \%{ }^{2}$ Leon Eisenberg, from Harvard Medical School in Boston, stated: "Epilepsy is an ancient disease that has been "explained," for as long as it has been perceived". Seizures are dramatic and frightening

egneuro, Volume 02, Issue 02, 2020 
as it can be expected in any place and time. ${ }^{6}$ Also, the stigma of seizure in a developing country like Nepal became a huge burden for the society. The belief of people and views of people can be frustrating while mentioning this. From demonic possession to curse from god makes the work challenging for it to control and its treatment. Kale $\mathrm{R}$ states that "The history of epilepsy can be summarized as 4,000 years of ignorance, superstition, and stigma, followed by 100 years of knowledge, superstition, and stigma. ${ }^{7}$

Though previous studies showed neurocysticercosis to be the most common cause of epilepsy in Nepal, we found Intracranial Hemorrhage as the most common cause of epilepsy may be because unlike other studies our samples are collected from neurosurgery department only. ${ }^{3-5}$

In our series, generalized tonic-clonic seizure (GTCS) was the most common type followed by a partial seizure. One hundred thirteen patients had GTCS and seven patients had a partial seizure. Other seizure types were not reported in our study; probably because sample collection was done only from the neurosurgery department. Although the age distribution of the incidence of epileptic seizures and epilepsy is bimodal, with two peaks of frequency: in childhood and in the elderly ${ }^{5,6}$ the presence of the pediatric population in our sample was minimal and patient managed under medical neurology were not included in this study.

We found the majority of patients are compliant with their medication. One hundred seven patients reported proper antiepileptic drug compliance and 11 patients reported poor antiepileptic drug compliance. Non-adherence is voluntary or involuntary failing to refill the prescription, taking doses in the wrong time, taking high or low doses of medication, discontinuing the treatment during treatment and failing to adhere on the agreed terms between health care worker and patient. ${ }^{8-10}$ Patients who were noncompliant to medication had significantly higher seizure frequency than those patients who were compliant to their medication. Although most of the seizures are effectively controlled with anti-epileptic drugs, $30 \%$ of patients seizures aren't effectively controlled despite best treatment strategy. ${ }^{11-13}$ Non-adherence to the antiepileptic drugs could be the major cause of seizure recurrence. Poor socioeconomic status and also poor availability of drugs in the locality are the major concerns. Patients non-adherent to the antiepileptics have poor seizure control and a high chance of recurrences. ${ }^{14-16}$ Our study has shown $90.2 \%$ of patients are compliant with the antiepileptic drugs whereas $9.8 \%$ of patients were non-adherent to the medications. Studies done in the USA showed 26\% non-adherence and Nigeria showed $67 \%$ non-adherence. ${ }^{17,18}$ Our study along with other study agreed on poor compliance associated with poor seizure control. ${ }^{14,19,20}$

Also, we reviewed the education level of the individual patients where there was a significant association between the education level and seizure control among those patients. Patient education is an important component in both seizure control and quality of life of patients. ${ }^{21}$ The knowledge, attitude, and practice of an individual and also the family members play a vital role in seizure control, adherence, and quality of life of that individual. Educating people about epilepsy, removing stigma related to it can be challenging in a developing country like Nepal but it could be beneficial in the future. It is important to change the knowledge, attitude, and practice of people where they believe epilepsy is a form of insanity, curse, demonic possession, etc. It is only then a good outcome can be expected.

Gum hypertrophy, a common side effect of phenytoin therapy was observed in two patients, dizziness was observed in one patient taking carbamazepine, and two patients taking valproic acid developed hepatitis during treatment requiring them to change their medication. There are various studies (case-control and cohort) in the Asian population to diagnose the cause for epilepsy. From the available literature, causes seem to be led by head injury, birth trauma, and intracranial infections, such as neurocysticercosis or meningoencephalitis and where socioeconomic development is better, head trauma, and stroke are the leading causes of epilepsy. ${ }^{5,22}$ In our study we mainly found $\mathrm{ICH}(39.2 \%)$ was the most common cause. Other causes were trauma $(36.7 \%)$, tumor $(15 \%)$, infection $(5.8 \%)$, congenital brain malformation (10\%), hydrocephalus (5.8\%) and ischemic CVA $(26.7 \%)$. Out of these causes for seizure trauma, tumor and hydrocephalus showed a 
statistically significant relationship with the seizure control. Gender distribution showed $34.2 \%$ and $65.8 \%$ for males and females respectively.

In our study, we found $87.5 \%$ of patients were under monotherapy and $12.5 \%$ of patients were under polytherapy. Mostly 1st generation antiepileptic drugs were used and were phenytoin, valproate, phenobarbital, carbamazepine, clonazepam. 2nd generation antiepileptic drugs (lamotrigine, topiramate, gabapentin, Levetiracetam) were used relatively low may be due to medical culture, practice, and while considering the socio-economic factor of the patients.

\section{Conclusion:}

Drug compliance played a pivotal role in determining good seizure control vs. poor seizure control. Additionally, the literacy level of the patient determined drug compliance and thus seizure control. More work is required in Nepal regarding the epidemiological studies of epilepsy. Adequate epidemiological studies will bring forward the true status of the disease in our setting and also help to legislate programs to reduce disease burden both at human resource and economic level.

\section{References:}

1. World health organization. Epilepsy fact sheet. [https://www.who.int/news-room/factsheets/detail/epilepsy]

2. Rajbhandari KC. Epilepsy in Nepal. Neurol J Southeast Asia 2003; 8:1-4.

3. Clinical Profile of Patients with Epilepsy in Tertiary Care Hospital in Nepal. Nepal Journal of Neuroscience 2012; 9:57-61.

4. Rajshekhar V, Joshi DD, Doanh NQ, van De N, Xiaonong Z. Taenia solium taeniosis/cysticercosis in Asia: epidemiology, impact and issues. Acta Trop. 2003; 87: 5360.

5. Mac TL, Tran DS, Quet F, Odermatt P, Preux PM, Tan CT. Epidemiology, aetiology, and clinical management of epilepsy in Asia: a systematic review. Lancet Neurol 2007; 6: 533-543.

6. de Boeur HM. Epilepsy; Social Consequences. In: Aminoff MJ, Daroff RB, editiors. Encyclopedia of Neurological Sciences. 2nd ed. London: Academic Press; 2014. P. 157-163.

7. Kale R. Bringing epilepsy out of the shadows. BMJ. 1997; 315:2-3.
8. Osterberg L., Blaschke T. Adherence to medication. NEnglJMed 2005;353(5):487-497.

9. Hugtenburg JG, Timmers L, Elders PJM, Vervloet M, van Dijk L. Definitions, variants, and causes of nonadherence with medication: a challenge for tailored interventions. Patient PreferAdherence 2013; 7:675-682.

10. Gabr WM, Shams M. Adherence to medication among outpatient adolescents with epilepsy. Saudi PharmJ 2015; 23:33-40

11. Devinsky O. Patients with refractory seizures. NEnglJMed 1999; 340:1565-1570.

12. Sillanpää M, Schmidt D. Long-term outcome of medically treated epilepsy. Seizure 2017; 44:211-216.

13. KwanP, Schachter SC, BrodieMJ. Drug-Resistant Epilepsy. N Engl J Med 2011; 369:919-926.

14. Jones RM, ButlerJA,ThomasVA,Peveler RC, Prevett M. Adherence to treatment in patients with epilepsy: Associations with seizure control and illness beliefs. Seizure 2006;15(7):504-508.

15. DekkerPA. World Health Organization. Mental and Behavioural Disorders Team, International League Against Epilepsy \& International Bureau for Epilepsy. 2002. Epilepsy: a manual for medical and clinical officers in Africa / P.A. Dekker, Rev. ed. World Health Organization. https://apps.who.int/iris/handle/10665/67453

16. SabatéE. Adherence to Long-Term Therapies: Evidence for Action. Geneva, Switzerland: World Health Organization; 2003.

17. Faught RE, Weiner JR, Guérin A, Cunnington MC, Duh MS. Impact of nonadherence to antiepileptic drugs on health care utilization and costs: findings from the RANSOM study. Epilepsia. 2009;50(3):501-509.

18. Johnbull OS, Farounbi B, Adeleye AO, Ogunrin O, Uche AP. Evaluation of factors influencing medication adherence in patients with epilepsy in rural communities of Kaduna State, Nigeria. Neuroscience \& Medicine. 2011;2(4):299-305.

19. Hovinga CA, Asato MR, Manjunath R, Wheless JW, Phelps SJ, Sheth RD, et al. Association of non-adherence to antiepileptic drugs and seizures, quality of life, and productivity: Survey of patients with epilepsy and physicians. Epilepsy Behav. 2008; 13:316-22.

20. Das AM, Ramamoorthy L, Narayan SK, Wadwekar V. Barriers of Drug Adherence among Patients with Epilepsy: in Tertiary Care Hospital, South India. J Caring Sci. 2018;7(4):177-181.

21. Garnett WR. Antiepileptic drug treatment: outcomes and adherence Pharmacotherapy, 2000 Aug;20:191S-199S.

22. YemadjeLP, HouinatoD, QuetF, Druet-Cabanac M, PreuxPM. Understanding the differences in prevalence of epilepsy in tropical regions. Epilepsia 2011; 52:1376-1381. 